\title{
Regenerating Retinal Axons of Goldfish Respond to a Repellent Guiding Component on Caudal Tectal Membranes of Adult Fish and Embryonic Chick
}

\author{
JOST VIELMETTER, JOCHEN WALTER, AND CLAUDIA A.O. STUERMER \\ Friedrich-Miescher-Laboratorium der Max-Planck-Gesellschaft (J.V., C.A.O.S.) and \\ Max-Planck-Institut für Entwicklungsbiologie (J.W.), Tübingen, Germany
}

\begin{abstract}
On a substrate of rostral/caudal tectal membrane stripes of adult fish, regenerating temporal retinal axons avoid the caudal membranes. Thus they behave like embryonic chick axons on chick E9 membranes. The caudal membranes of adult fish contain a repellent component that, as has previously been shown in the chick, is inactivated by the enzyme PI-PLC. Fish axons respond not only to their own but also to the repellent component of embryonic chick membranes. Fish and more so chick E9 caudal membranes have an outgrowth reducing effect on fish axons that is also abolished by PI-PLC treatment and is weaker on chick E16 membranes. Thus adult fish tecta express a guiding component for retinal axons related to that in the embryonic chick.
\end{abstract}

Key words: growth cone guidance, retinotectal projection, choice assay, repulsive component, GPI-linked membrane proteins

The projection of retinal ganglion cells onto the tectum is organized by the same rules in different species such as fish and birds. Axons from ganglion cells along the dorsoventral and temporonasal axes of the retina terminate retinotopically along the ventrodorsal and rostrocaudal axes of the tectum, respectively. The similarity of the spatial organization of the axon terminals over the tectum suggests that the mechanisms that govern its formation may be the same or related in different species and may act across species boundaries.

Various models have been discussed to explain how axons manage to find their targets in the tectum (reviewed in Gaze, '70; Stuermer, '89). Among them, the "gradient theory" proposes a graded distribution of cell surface markers on the tectum that are recognized by the retinal growth cones (Sperry, '63; Fraser, '80; Bonhoeffer and Gierer, '84; Gierer, '87). Not only the pathways of retinal axons seen in fixed preparations but also the behavior of the growing axons in recent in vitro studies are consistent with this theory. In these in vitro assays (Walter et al., '87a,b), cell surface membranes from the rostral and caudal tectum are arranged in narrow alternating stripes and serve as a substrate for retinal axons from temporal or nasal retinal explants. On this carpet, temporal axons, whether from chick (Walter et al., '87a) or fish (Vielmetter and Stuermer, '89) accumulate on rostral membranes, i.e., on membranes from their retinotopically related tectal half. Nasal axons, however, grow randomly over the carpet. A similar behavior has been demonstrated for temporal and nasal axons from embryonic mouse on membranes from the mouse superior colliculus (Godement and Bonhoeffer, '89). Two differences, however, exist between the fish and the chick and mouse choice assay concerning the source of the membranes and the type of axons used. The chick membranes are taken from embryos younger than E16 and the mouse membranes from embryos or young postnatals (P2), because membranes of older chick embryos and older mice have lost their guiding influence (Walter et al., '87a; Godement and Bonhoeffer, '89). Axons are from chick E6 or mouse E15-16 retinae, which extend axons most reliably in culture. The membranes for the fish assay, in contrast, are derived from tecta of adult goldfish and the axons are regenerating ones from explants of adult fish retinae (Vielmetter and Stuermer, '89).

Fish retinotectal development proceeds throughout the animal's life (Easter, '85), with axons from continuously produced new ganglion cells growing into the tectum and finding their retinotopic home. In the chick and the mouse,

\footnotetext{
Accepted May 29, 1991.

Address reprint requests to C.A.O. Stuermer, who is now at the Faculty of Biology, University of Konstanz, D-7750 Konstanz, Germany.

J. Vielmetter is now at the California Institute of Technology, Pasadena, CA 91125 .
} 
however, retinal axons settle in the tectum only during well-defined periods of embryogenesis (Crossland et al., '75; Godement et al., '84). The ongoing growth in the fish correlates with the presence of guidance components on membranes of adult tecta seen in vitro, and continuous expression of these components could account for the capacity of fish to regenerate their axons, to their retinotopic target sites in the tectum (Vielmetter and Stuermer, '89).

The similarity of axon responses in vitro to tectal membrane associated components and the temporal differences in the presence of guiding components in the chick and mouse, on the one hand, and fish, on the other, led us to explore whether this component in the fish is the same as that in the chick and possibly the same as in the mouse. The chick component has been characterized and the response of the temporal axons has been shown not to be evoked by a special attractiveness of the rostral membranes but by a repellent component that is associated with the caudal tectum (Walter et al., '87b). Membranes of chicks older than E16 have lost their repellent influence. Furthermore, the repellent component on membranes (younger than E16) can be inactivated by heat treatment (Walter et al., ' $87 \mathrm{~b}$ ) or by exposing the membranes to the enzyme phosphatidylinositol specific phospholipase C (PI-PLC) (Walter et al., '90). This enzyme cleaves the glycosyl-phosphatidylinositol (GPI) anchor of proteins and indicates that the repellent guiding component is a GPI-anchored protein in the chick (Ferguson and Williams, '88; Low and Saltiel, '88).

If at least some of the guidance in the tectum of adult fish is mediated by repellent component that is of a similar nature to that of chick embryos, then it may be sensitive to the same treatments that result in the loss of this component in the chick. One aim of this study is to resolve this point. The first set of experiments analyzes the response of regenerating goldfish retinal axons to fish tectal membranes after heat treatment or exposure to PI-PLC in two in vitro assays, the choice assay (Walter et al., '87a; Vielmetter and Stuermer, '89) and the outgrowth assay (Vielmetter and Stuermer, '89). To determine whether the membrane-associated component of the embryonic chick and that of the adult fish tectum are similar molecules and equally effective on fish axons, a series of cross species experiments is performed. The growth behavior of regenerating fish axons on embryonic chick membranes, which are either untreated or treated with heat or PI-PLC or which are derived from late embryonic stages, is determined. Preliminary accounts of this work have been published as an abstract (Vielmetter et al., '90).

\section{MATERIAL AND METHODS}

Fragments of cell surface membranes were prepared from rostral or caudal thirds of embryonic chick and adult $(7-10 \mathrm{~cm})$ goldfish tecta as described by Walter et al. ('87a) and Vielmetter and Stuermer ('89). In brief, tectal hemispheres from 10 goldfish (7-10 cm body length) were isolated, transferred into Leibovitz medium (L15 Gibco), and divided. Rostral and caudal thirds were pooled separately and homogenized in $250 \mu \mathrm{l}$ of homogenization solution consisting of $10 \mathrm{mM}$ Tris-HCl buffer ( $\mathrm{pH} 7.4), 1.5 \mathrm{mM}$ $\mathrm{CaCl}_{2}, 1 \mathrm{mM}$ spermidine (Serva) (to stabilize the nuclei), the glucosidase inhibitor 2,3-dehydro-2-deoxy-N-acetylneuraminic acid (Sigma), and the following protease inhibi- tors; aprotinine $(25 \mu \mathrm{g} / \mathrm{ml})$, leupeptine $(25 \mu \mathrm{g} / \mathrm{ml})$, and pepstatin $(5 \mu \mathrm{g} / \mathrm{ml})$. The homogenate was centrifuged for 10 minutes at $25,000 \mathrm{rpm}$ in a sucrose step gradient (upper phase $50 \mu \mathrm{l}$ of $5 \%$ sucrose; lower phase $15 \mu \mathrm{l}$ of $50 \%$ sucrose) in a Beckman ultracentrifuge. The resulting interband was washed in $1 \mathrm{ml}$ of PBS and repelleted for 10 minutes at $4^{\circ} \mathrm{C}$ in Eppendorf reaction tubes in a Heraeus biofuge. After washing the pellet twice in PBS containing the same protease and glucosidase inhibitors as found in the homogenization buffer, it was resuspended in $1 \mathrm{ml}$ of PBS without inhibitors. The membrane concentration was determined by its optical density measured with a spectrophotometer (Shimadzu) at $220 \mathrm{~nm}$. A $50-\mu l$ sample of the membrane suspension was solubilized in $750 \mu l$ of PBS with $2 \%$ SDS to measure the actual protein concentration. The membrane suspension was either diluted or concentrated to the desired optical density of 0.1 (which is approximately $100 \mathrm{mg} / \mathrm{ml}$ protein) before use and before heat and PI-PLC treatment.

Similar procedures were used to obtain tectal membranes from chick embryos, except that the tectal tissue was collected in Hank's Salt solution (Walter et al., '87a).

Heat treatment of fish tectal membranes: Fish tectal membrane suspensions (O.D., 0.1) were transferred into $15-\mathrm{ml}$ plastic centrifuge tubes and were heated in a water bath for 10 minutes at temperatures ranging from $45^{\circ} \mathrm{C}$ to $60^{\circ} \mathrm{C}$

PI-PLC-treatment of fish and chick tectal membranes. After exchanging PBS in tectal membranes, against an equal volume of Tris-buffer (20 mM Tris-HCL, pH 7.4 and protease inhibitors) $1 \mathrm{mU} / \mathrm{ml}$ PI-PLC (Boehringer-Mannheim) was added to the membrane suspension. The suspension was incubated for 1 hour at $37^{\circ} \mathrm{C}$ in a water bath. Incubation was stopped by adding $\mathrm{KCl}(1 \mathrm{M}$ final concentration) and pelleting the membranes (30 min., $100.000 \mathrm{~g})$. In choice assay experiments, an inhibitor of PI-PLC, $0.5 \mathrm{mM}$ chloromercuryphenyl-sulfonic acid (Sigma), was added to the stop buffer. The membranes were washed twice with PBS.

Preparation of membrane stripes. Membrane stripes (Fig. 1) were prepared according to Walter et al. ('87a). To generate alternating stripes of rostral and caudal membranes, a Nucleopore filter $(0.1 \mu \mathrm{m}$ pore diameter $)$ was placed onto a special silicon matrix (Walter et al., '87a). In its center, this matrix contains an area of parallel bars separated by channels. In contact with the filter, the bars protect the underlying filter pores in a striped pattern. The first membrane suspension $(150 \mu \mathrm{I})$ is applied to the filter, and by low pressure suction ( $2 \mathrm{~min}, 1.7 \mathrm{Pascal}$ ) through the channels, the membrane particles attach to the filter in parallel stripes and subsequently occlude the pores in this region. The second membranes $(150 \mu \mathrm{l})$ are sucked to the filter (1.5 min, 1.9 Pascal) after replacing the silicon matrix by a nylon tissue. Suction is only effective through pores previously protected by the bars of the silicon matrix. The rostral membranes were applied first and the caudal membranes second, or the reverse. The membranes applied first were mixed with fluorescent beads to facilitate their identification.

Depending on the experiment, stripes were made using tectal membranes from adult fish or embryonic chick and using treated (see above) or untreated membranes. Fish retinal explants, staining of retinal axons with DiI and culture conditions, were as described in Vielmetter and Stuermer ('89). 


\section{temporal retina}
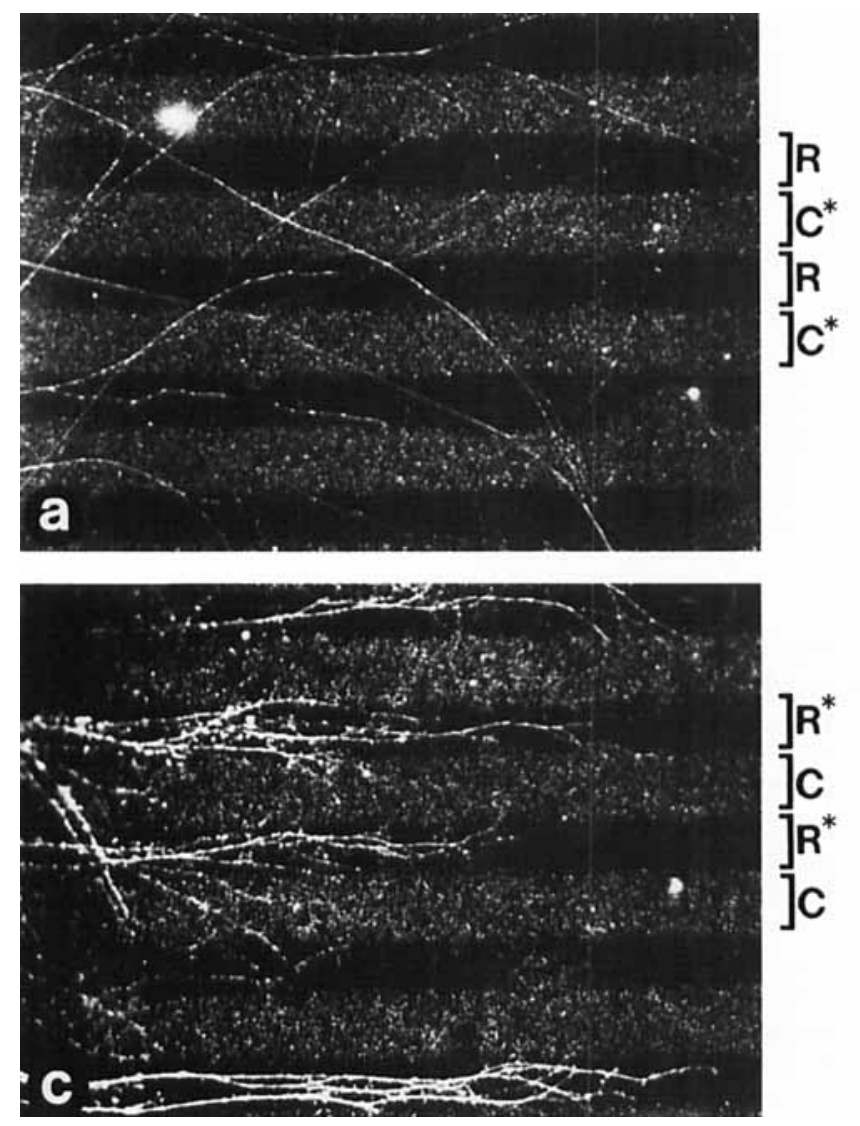

Fig. 1. Photomicrographs of DiI-stained axons from fish temporal $(a, c)$ and nasal (b, d) retinal explants on rostral (R) and caudal (C) tectal membranes of fish. The retinal explants (to the left) are not shown. Caudal membranes were mixed with fluorescent beads. One type of membrane was treated with the enzyme PI-PLC prior to application to the filter support, in (a) and (b) the caudal $\left(\mathrm{C}^{*}\right)$ and in (c) and (d) the rostral $\left(R^{*}\right)$ membranes. (a) Temporal axons no longer segregate but

\section{Quantitative growth assay}

The quantitative growth assay (Vielmetter and Stuermer, '89) was used to compare the degree to which rostral and caudal tectal membranes of the fish or chick, prior to and after PI-PLC treatment, support the outgrowth of fish axons from retinal explants. Membranes of rostral and caudal tectum (fish or chick, treated or untreated) were prepared as described above and centrifuged down to the bottom of wells of 96-well dishes (NUNC). Small retinal explants $(200 \times 200 \mu \mathrm{m})$ of defined positional origin were distributed systematically over the wells such that $50 \%$ of the wells with rostral membranes and $50 \%$ of the wells with caudal membranes received temporal mini explants. The other $50 \%$ of the wells with rostral or caudal membranes obtained nasal miniexplants. After 48 hours in culture, the number of axons per explant was determined. Within each of the experimental groups, the number of axons of all explants was pooled.

In these experiments, the absolute number of axons varies between the experimental groups. This is explained

\section{nasal retina}
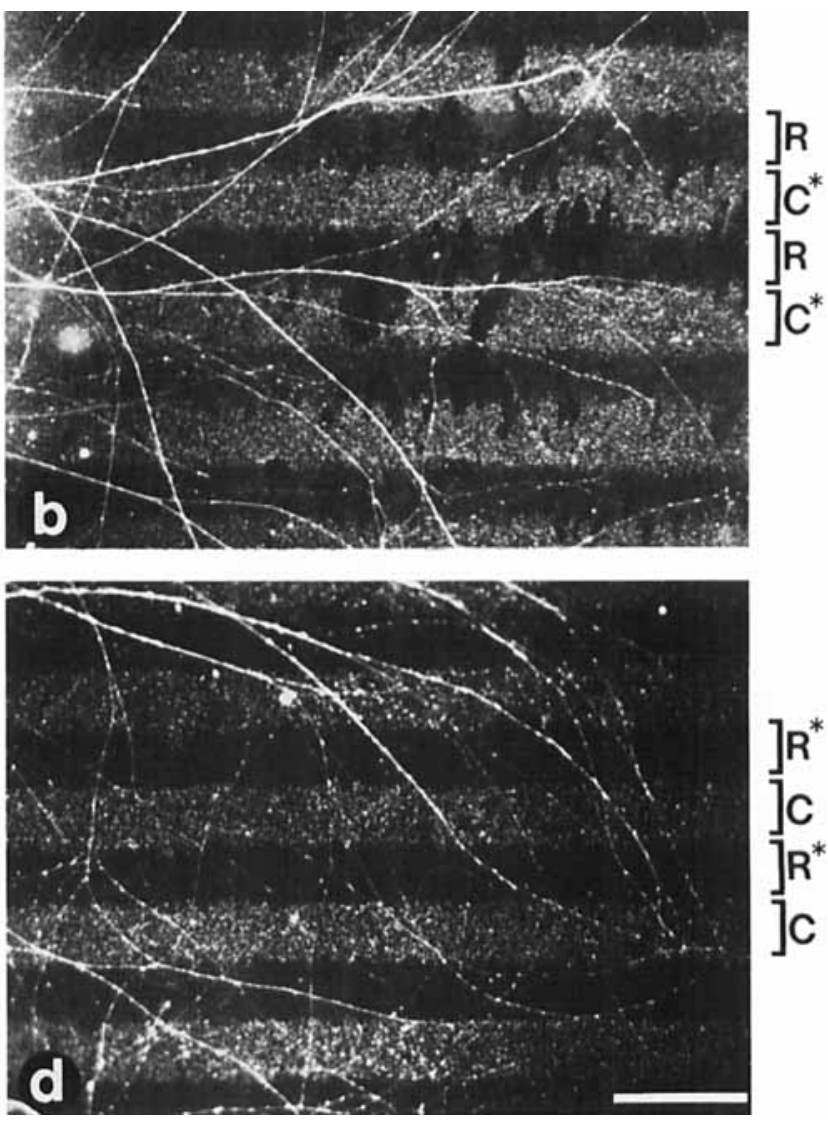

grow randomly over the striped membrane carpet when caudal membranes were PI-PLC treated. (b) Nasal axons grow, as usual, randomly over the carpet. (c) Temporal axons avoid the caudal membranes and accumulate on rostral (PI-PLC treated) membranes. (d) Nasal axons grow randomly over the membrane carpet. Calibration bar for (a-d) in (d): $200 \mu \mathrm{m}$.

by a better outgrowth of one batch of retinae as compared to another. In each experimental group, however, the explants derive from the same retina. This allows comparison of the relative differences of temporal versus nasal axon outgrowth on rostral versus caudal membranes.

\section{RESULTS}

The response of regenerating temporal and nasal fish axons to tectal cell membrane associated components is explored. The in vitro choice and outgrowth assay are used in parallel in four groups of experiments. They address the questions: (1) whether the growth behavior of fish temporal axons is caused by a repellent component on fish tectal membranes, (2) whether fish axons respond to the repellent component on chick caudal membranes, (3) whether fish axons are sensitive to the inactivation of the repellent activity on chick membranes, and (4) whether E16 chick caudal membranes have lost their repellent influence on fish axons. 
temporal retina

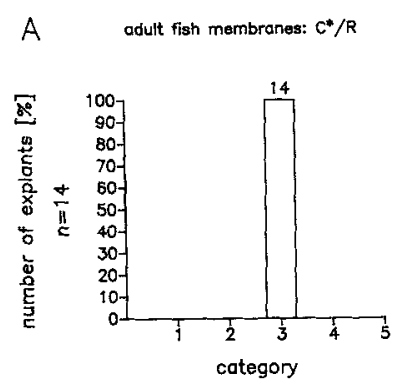

C odult fish membranes: $C / R^{*}$

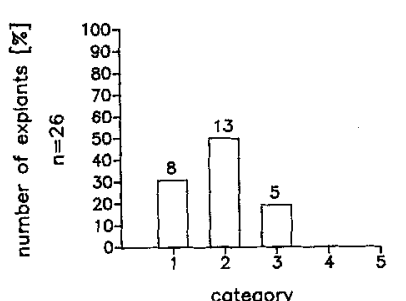

category
$B \quad$ odult fish membranes: $C^{*} / R$
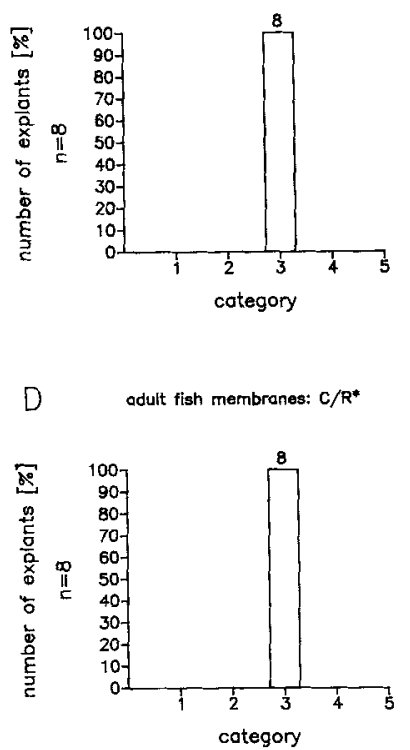

Fig. 2. Histograms showing the distribution of preparations (exemplified in Fig. 1) over the scoring categories 1 to 5. (For explanation of categories, see Results). Scores for $\mathbf{A}$ temporal axons and $\mathbf{B}$ nasal axons after PI-PLC treatment of caudal membranes $\left(\mathbf{C}^{*}\right) . \mathbf{C}$ temporal and $\mathbf{D}$ nasal axons after PI-PLC treatment of rostral membranes $\left(R^{*}\right)$. The numbers on top of each bar give the absolute number of preparations for each category.

\section{Caudal tectal membranes from adult goldfish have a repellent influence on regenerating temporal retinal goldfish axons}

Choice assay: Fish axons on PI-PLC treated fish tectal membranes. The treatment of tectal membranes of fish with PI-PLC efficiently eliminated the repulsive property of caudal membranes from adult fish tecta. Even though this treatment did not significantly influence the growth supporting capacity of these membranes. Figure la illustrates a typical example in which regenerating temporal axons from adult goldfish grow on alternating membrane stripes of rostral and PI-PLC-treated caudal tectal membranes. The axons did not accumulate on the rostral membrane stripes as they would if untreated membranes were used (Vielmetter and Stuermer, '89). Figure 1c illustrates a control experiment in which rostral instead of caudal membranes were PI-PLC-treated. Temporal axons accumulated on rostral membranes as they would on untreated membranes suggesting that PI-PLC-treatment of rostral membranes had no influence on the choice behavior of temporal axons.

Nasal axons did not change their behavior in the choice assay when either caudal or rostral membranes were pretreated with PI-PLC, as shown in Figure 1b,d. In both cases nasal axons grew randomly over rostral and caudal membrane stripes as they did on untreated membranes (Vielmetter and Stuermer, '89).

A quantitative overview of these results is given in the histograms in Figure 2A-D. Preparations were classified according to five categories as in an earlier study (Vielmet-

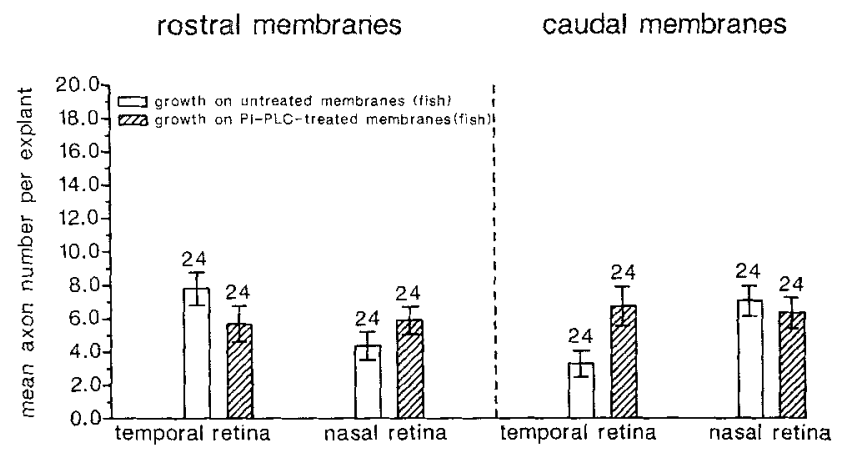

Fig. 3. Histogram showing the numbers of axons emerging from temporal and nasal retinal explants on either rostral or caudal tectal membranes of fish. Membranes untreated (open bars), membranes PI-PLC treated (hatched bars). The reduced outgrowth of temporal axons on untreated caudal membranes is no longer seen on PI-PLC treated caudal membranes. On top of each bar, the number of preparations and the standard deviation.

ter and Stuermer, '89). Category 1 represents preparations in which axons clearly accumulate on rostral membranes. Preparations fall into category 2 when their segregation onto rostral membranes is less distinct but still visible. Category 3 represents preparations with random growth patterns. Category 4 includes preparations with moderate segregation onto caudal membranes, and category 5 with distinct segregation onto caudal membranes. Photographs of the axonal growth patterns exemplifying these categories are given in Vielmetter and Stuermer ('89).

Outgrowth assay: Fish axons on PI-PLC treated fish tectal membranes. We showed earlier (Vielmetter and Stuermer, '89) that the outgrowth from explants of the temporal retina is reduced on caudal tectal membranes as opposed to rostral membranes. Here, we investigated whether PI-PLC-treatment of tectal membranes would have an influence on the amount of axonal outgrowth. The outgrowth of temporal and nasal retinal axons when offered either untreated or PI-PLC-treated tectal membranes as the sole substrate was compared. The results of these experiments are summarized in the histograms in Figure 3. The control experiment (open bars in Fig. 3) confirms earlier results (Vielmetter and Stuermer, '89). The outgrowth of temporal axons on caudal membranes is markedly smaller than on rostral membranes. However, following PI-PLC treatment (hatched bars in Fig. 3) the outgrowth of temporal retina on caudal membranes is no longer reduced (compare Fig. 5 with treated and untreated chick caudal membranes), indicating that PI-PLC has improved the permissivity of caudal membranes for temporal axons.

The growth rate of nasal axons is unaffected by PI-PLC treatment of the caudal membranes and is equally high as on untreated caudal membranes (Fig. 3). Unusual and unexplained is the lower outgrowth of nasal axons on untreated rostral membranes. This was not seen in our earlier study (Vielmetter and Stuermer, '89, Fig. 6) where many more explants were used.

Choice assay: Fish axons on heat treated fish tectal membranes. Exposing the chick caudal membranes to heat $\left(63^{\circ} \mathrm{C}, 8 \mathrm{~min}\right)$ results in a selective inactivation of the repellent component without destroying the growth permissivity of the membranes (Walter et al., ' $87 \mathrm{~b}$ ). For fish, however, treatment of membranes with temperatures of up to $49^{\circ} \mathrm{C}$ for 10 minutes did not eliminate the repellent 
influence of the caudal membranes. Higher temperatures completely abolished the growth permissivity of both rostral and caudal membranes. This was concluded from an unusual behavior of temporal and nasal axons. After heat treating the caudal membranes nasal axons segregated on rostral membranes, and after heat treating rostral membranes both nasal and temporal axons preferred the caudal over the rostral membranes.

\section{Cross-species experiments reveal that regenerating retinal axons from adult fish recognize a repellent component on caudal tectal membranes from embryonic chick}

Choice assay: Fish axons on chick E9 tectal membranes. There are striking similarities in the behavior of chick and fish axons in response to the tectal membrane properties. To test whether the tectal membrane properties of the embryonic chick and regenerating adult fish are alike, we performed a cross-species experiment and explored the behavior of regenerating retinal axons from adult goldfish on tectal membranes from embryonic chick tecta, in both the choice assay and the outgrowth assay.

Figure $4 a$ shows regenerating temporal retinal axons from adult goldfish extending on alternating rostral and caudal membrane stripes from chick E9 tecta. Temporal axons clearly accumulated on the rostral membrane stripes. In contrast to their growth pattern on fish membranes, they hardly ever crossed the caudal membrane stripes of the chick.

Regenerating nasal retinal axons from fish behaved differently on chick E9 tectal membranes than on membranes from adult goldfish tecta (Fig. 4b) and behaved differently from chick nasal axons on these membranes. Instead of crossing randomly over rostral and caudal membrane stripes, they accumulated, like temporal axons, on rostral membranes. However, their segregation was not as distinct as that of temporal axons and more axons crossed the caudal membrane stripes.

In these experiments the preparation of membrane stripes was such that caudal membranes were applied first and rostral membranes second. In a second series of experiments, the order of membrane application was reversed. The same type of responses as described above were observed. A quantitative summary of the cross-species choice assay experiments are given in the histogram in Figure 5A,B.

Outgrowth assay: Fish axons on chick E9 tectal membranes. In the quantitative growth assay with chick E9 membranes (Fig. 6A,B), the outgrowth from temporal fish explants on caudal tectal chick membranes was almost completely suppressed. The outgrowth of nasal axons was reduced compared to their outgrowth on rostral membranes. On rostral membranes of embryonic chick, however, outgrowth of temporal and nasal axons was equally high and much higher than on tectal membranes of adult fish tecta (Vielmetter and Stuermer, '89), suggesting that chick rostral membranes have growth stimulating properties exceeding those of fish membranes.

\section{The repellent influence of chick E9 caudal membranes on fish retinal axons is lost after PI-PLC treatment}

Choice assay: Fish axons on PI-PLC treated chick E9 membranes. Whether regenerating retinal axons from adult fish respond to a repellent component on embryonic chick tectal membranes (as they do on adult fish tectal membranes and as embryonic chick retinal axons do on embryonic chick tectal membranes) was addressed by using the same experimental paradigm as in the preceeding cross-species choice and outgrowth assays, but either caudal or rostral embryonic chick tectal membranes were pretreated with PI-PLC. Tectal membranes were from E9 chick embryos.

The results of the choice assay experiments are illustrated in Figure 4c-f. Figure 4c shows temporal axons growing on alternating stripes of PI-PLC-treated caudal and untreated rostral membranes. Temporal axons no longer discriminated between the membrane stripes. Figure $4 \mathrm{e}$ represents a control experiment in which temporal axons grow on alternating stripes of untreated caudal and PI-PLC-treated rostral membranes. The segregation of temporal axons is clearly visible.

Fish nasal axons responded in a similar way to PI-PLCtreated embryonic chick tectal membranes (Fig. 4d,f). Figure 4d shows fish nasal axons on chick PI-PLC-treated caudal and untreated rostral membranes. No segregation is visible under these conditions. In the control experiment (Fig. 4f) in which nasal axons grew on untreated chick caudal and PI-PLC-treated rostral membranes, the axons exhibited a slight tendency to accumulate on rostral membranes, but less than on membranes without PI-PLCtreatment. A summary of these results is illustrated in the histogram in Figure 5C-F.

Outgrowth assay: Fish axons on PI-PLC treated chick E9 membranes. Whether the suppression of outgrowth of fish temporal axons and the reduction of outgrowth of fish nasal axons on chick E9 caudal tectal membranes are also caused by a PI-PLC-sensitive membrane component was answered by providing PI-PLC-treated caudal or rostral membranes of chick E9 in the outgrowth assay. As controls, untreated membranes of the same source were offered as a substrate (Fig. 6A). The suppression of outgrowth of temporal axons on untreated caudal membranes is not seen when temporal axons are growing on PI-PLC-treated membranes. Further, the outgrowth of nasal axons, reduced on untreated caudal membranes, is almost as high as on rostral membranes after the caudal membranes were PIPLC-treated. The amount of temporal and nasal axons on PI-PLC-treated rostral membranes is in the same range as on untreated rostral membranes.

Fish axons are sensitive to the age-dependent decline of the repellent component of the chick caudal tectum

Choice assay: Fish axons on chick E16 tectal membranes. Chick temporal axons do not recognize any differences between caudal and rostral membranes from tecta of E16 embryos (Walter et al., '87a). Whether this would apply to fish axons as well was tested in cross-species choice and outgrowth assays. The results of the choice assay experiments are illustrated in Figure $4 \mathrm{~g}, \mathrm{~h}$ and quantified in Figure 5G,H. On alternating caudal and rostral membranes from E16 embryos, fish regenerating temporal retinal axons still accumulate on rostral membranes (Fig. 4g). Only nasal fish axons no longer distinguish between E16 caudal and rostral membranes (Fig. 4h). On chick E16 membranes there are more preparations with moderate segregation patterns (category 2) of temporal axons than with chick E9 tectal membranes (compare Fig. 5A). Nasal axons exhibit in 


\section{temporal retina}
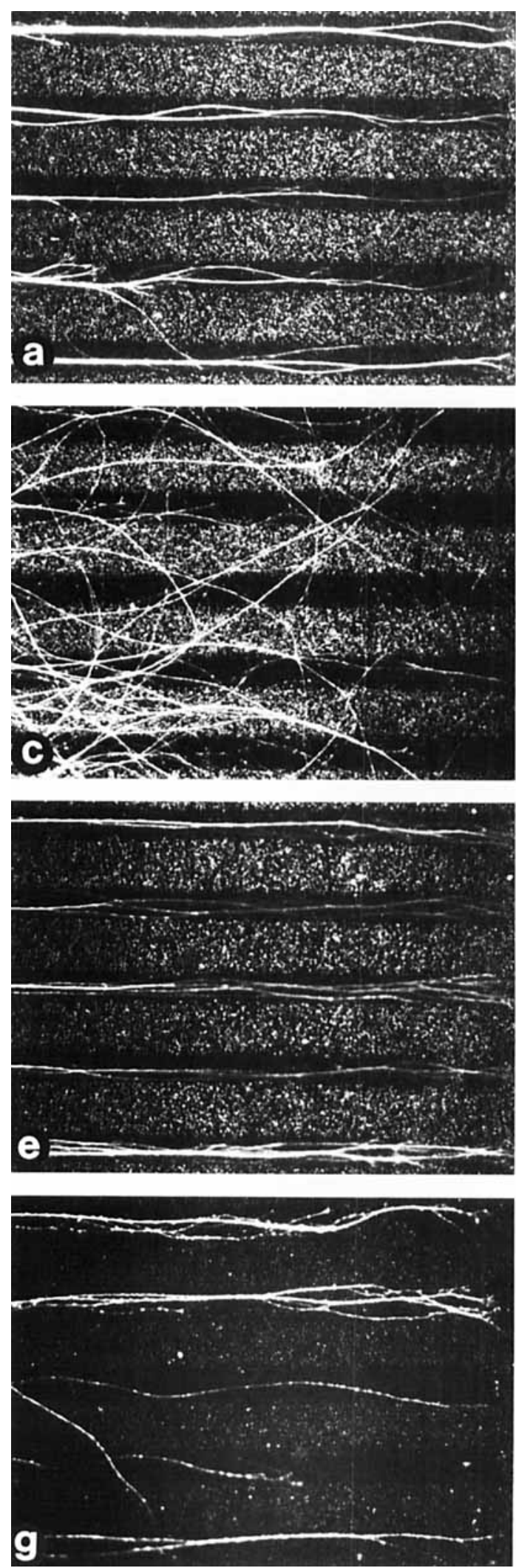

\section{nasal retina}
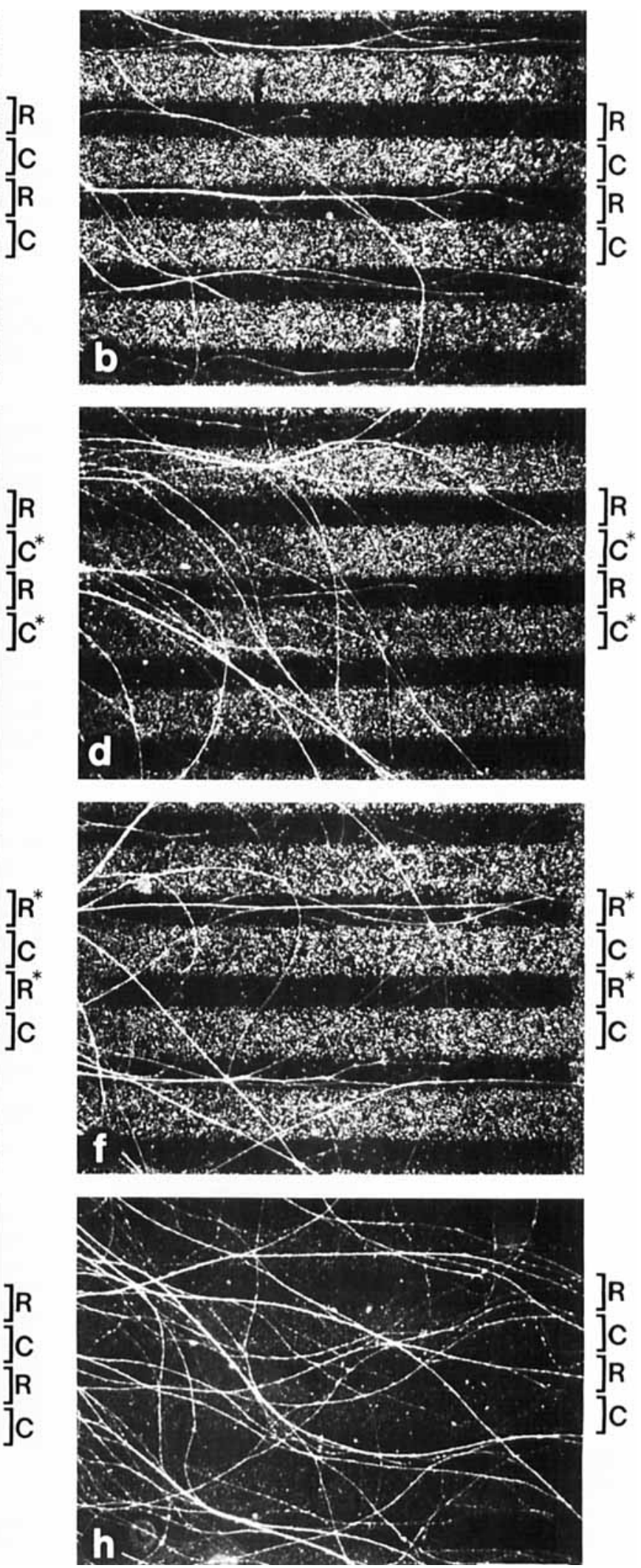
only one case a moderate segregation onto rostral membranes (Fig. $5 \mathrm{H}$ ). In all other cases they grow randomly over the membrane stripes (category 3 ).

Outgrowth assay: Fish axons on chick E16 tectal membranes. Whether the inhibitory effect of embryonic chick tectal membranes on the outgrowth of regenerating retinal axons from adult fish would also decline with age was tested in outgrowth assays using caudal and rostral tectal membranes from chick E9 and E16, respectively (Fig. 6B). There still is an inhibitory effect of caudal membranes on the outgrowth of temporal axons, but it is less pronounced than on chick E9 caudal membranes. As opposed to E9 membranes, the outgrowth of nasal axons is no longer reduced on E16 membranes.

\section{DISCUSSION}

Tectal membranes of adult goldfish express a guiding component for retinal axons (Vielmetter and Stuermer, '89). The foregoing experiments have demonstrated that this component on fish tectal membranes resembles, in its distribution and influence on retinal axons, the deflecting or repellent guiding component that has been identified in chick embryos (Walter et al., ' $87 a, b$ ). In adult fish the guiding component is associated, as in embryonic chick, with membranes of the caudal tectum. It repels temporal axons from caudal tectal membranes in the in vitro stripe assay, and they consequently accumulate on rostral membrane stripes.

The interesting difference between fish and chick, however, is that the fish tectum apparently retains this guiding component into adulthood, whereas the chick does not. In the chick the response of axons is elicited by membranes from embryos younger E14 but not by membranes from older embryos (Walter et al., ' $87 \mathrm{a}$ ). The guiding component in chick is therefore either reduced in amount or in its activity in more mature birds.

As has previously been demonstrated for chick caudal membranes (Walter et al., '90), the repellent guiding component in fish is inactivated by treating the caudal membranes with the enzyme PI-PLC. The present study has shown that the caudal membranes of fish also lose their repellent influence on fish temporal axons upon exposure to PI-PLC. Thus the fish component is similar to the chick component not only in its distribution and influence on temporal axons, but also in its linkage to the membranes. Both the fish and chick components must belong into a group of molecules that are linked to the membrane by a GPI anchor or they are associated with a GPI-linked molecule(s).

Fig. 4. Photomicrographs of Di-stained fish temporal and nasal retinal axons on alternating stripes of rostral and caudal tectal membranes of chick embryos. Caudal membranes were mixed with fluorescent beads. The retinal explants (to the left) are not shown. (a-f) Membranes of chick E9. (g, h) Membranes of chick E16. (a, b) Temporal and nasal axons accumulate on rostral chick E9-membranes but temporal axons (a) more strictly than (b) nasal axons. (c, d) After treatment of the caudal membranes with PI-PLC $\left(\mathrm{C}^{*}\right)$, both, temporal (c) and nasal (d) axons cross randomly over the chick E9-membrane carpet. (e, f) Rostral E9 chick membranes were PI-PLC treated $\left(\mathrm{R}^{*}\right)$ Temporal axons (e) accumulate as in (a), strictly on rostral membranes and (f) nasal axons to a much lesser extent. (g, h) Rostral and caudal membranes of chick E16. Fish temporal axons still accumulate on rostral membranes (g) but nasal axons cross randomly over the stripes (h). Calibration bar in h (for $\mathrm{a}-\mathrm{h}$ ): $200 \mu \mathrm{m}$. temporal reting

$A$

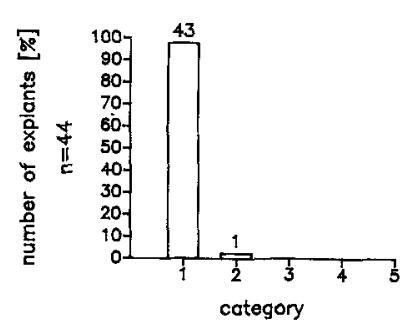

C

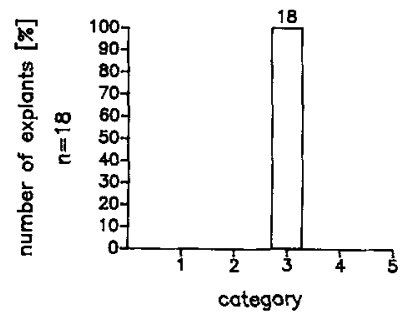

E

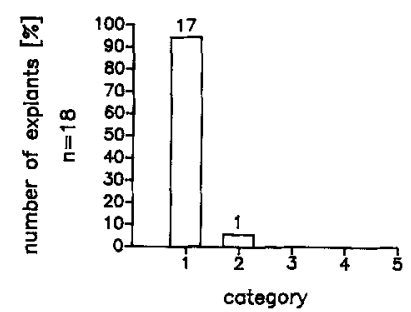

G

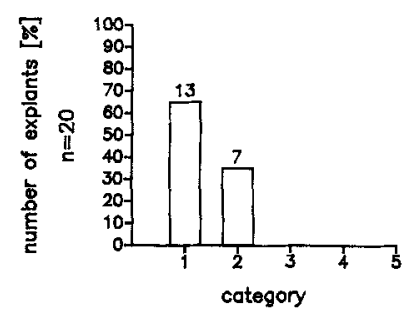

nasal retina

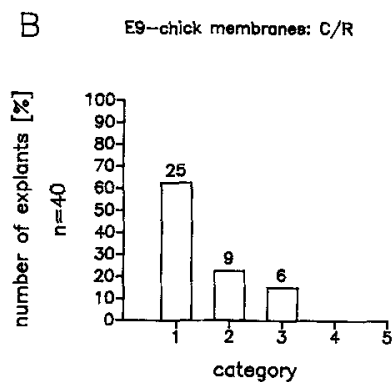

De-chick membranes: $C^{*} / R$

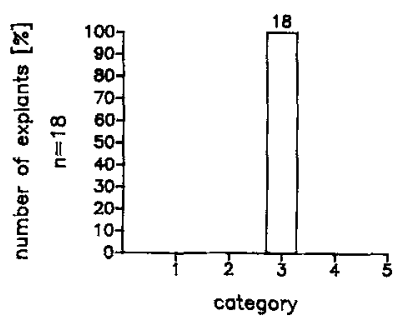

F
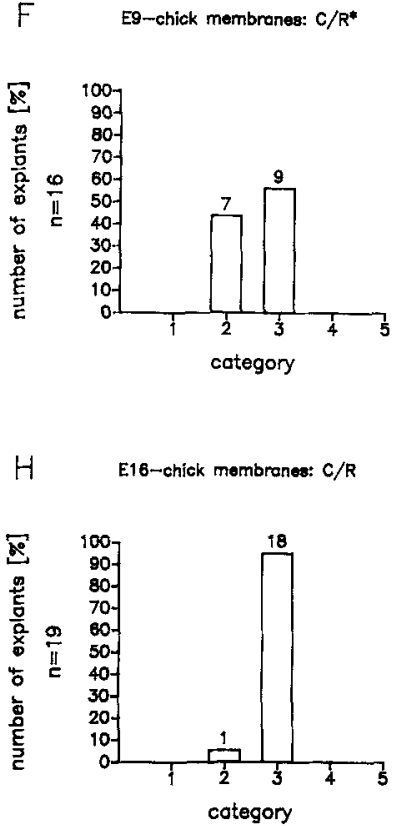

Fig. 5. Histograms giving the distribution of the preparations exemplified in Figure 4. Conventions as in Figure 3. A-F. Fish axons on, chick E9 membranes; G, H: on chick E16 membranes. A,B. Rostral and caudal membranes untreated. C,D. Caudal membranes PI-PLC treated (C*). E,F. Rostral membranes PI-PLC treated $\left(\mathbf{R}^{*}\right)$. G,H. Rostral and caudal membranes untreated.

The reaction of fish retinal axons to the properties of the fish caudal membranes in the in vitro choice assay is parallelled by the axon behavior observed in the outgrowth assay, the second in vitro assay of this study. In contrast to the choice assay, the outgrowth assay offers one membrane 
A

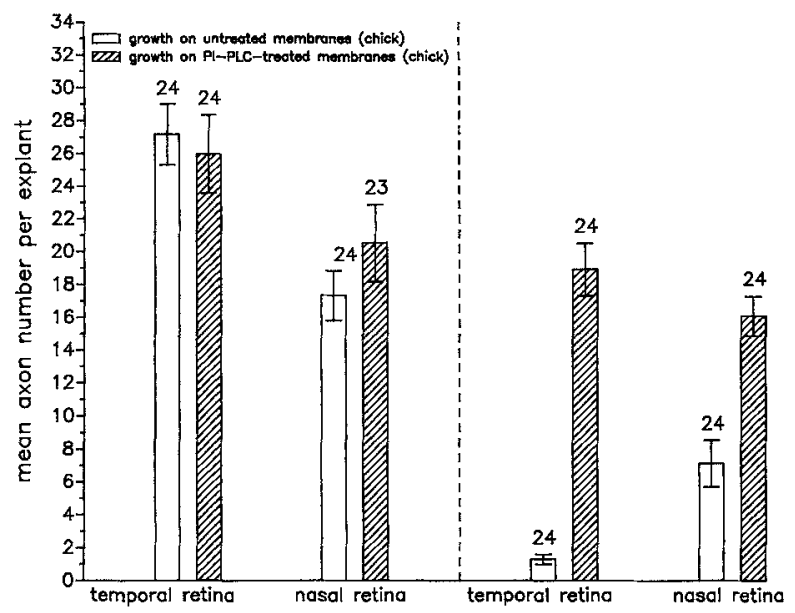

B

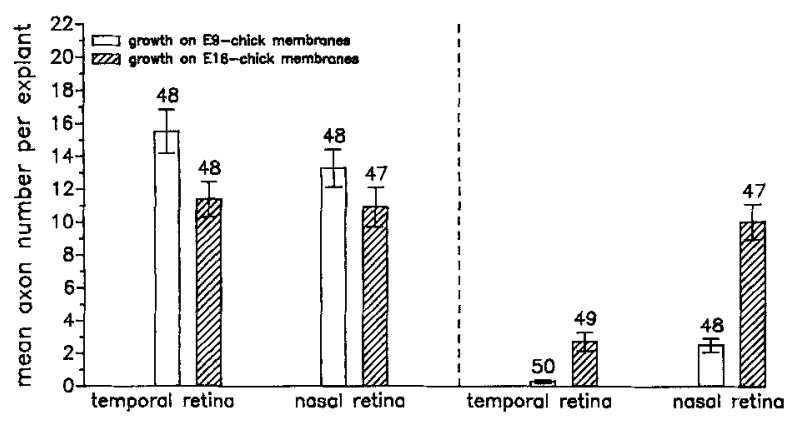

Fig. 6. Histograms showing the number of axons emerging from temporal and nasal fish retinal explants on either rostral or caudal tectal membranes of chick. A. Growth on chick E9 membranes on untreated (open bars) and PI-PLC treated membranes (hatched bars). On top of each bar the number of retinal explants and the standard deviation. B. Growth on chick E9 (open bars) and chick E16 (hatched bars) membranes.

type as the sole substrate. Fish caudal membranes allow the outgrowth of only half as many temporal axons as on rostral membranes (Vielmetter and Stuermer, '89). This reduction of outgrowth on caudal membranes is alleviated and reaches the same level as on rostral membranes after PI-PLC treatment of the caudal membranes. This treatment abrogates the repellent influence of the caudal membranes in the choice assay and also abolishes the growthinhibiting effect. Thus both activities of the membranes are mediated by a GPI-linked molecule(s).

Several molecules are known to be linked to cells in the nervous system by GPI. Among them are the cell adhesion molecules NCAM 120 (He et al., '86) and F 11 in the chick (Brümmendorf et al., '89). Loss of these and other molecules with such an anchor does not noticably affect the general growth permissivity of the membranes. This is concluded from finding that the number of axons growing on PI-PLC treated rostral membranes is as high as on untreated rostral membranes. Thus PI-PLC treatment affects specifically the caudal membranes and improves their growth permissivity. Alteration of the membrane permissivity of fish caudal membranes by PI-PLC only influences the outgrowth of temporal and not that of nasal axons. This situation correlates with that in the choice assay where nasal axons proved to be less sensitive to the caudal membrane component than temporal axons.

These evidences show that the repellent guiding component in the choice and the outgrowth reducing component in the growth assay are on the same fraction of membranes and act on the same subpopulation of axons. This correlation includes the possibility that the outgrowth reducing component and the repellent guiding component may be identical.

In addition, in both fish and chick the guiding component is concentrated in the caudal tectum, only temporal axons respond to it, and it is sensitive to PI-PLC. All of these similarities suggest that the component in adult fish and embryonic chick may be related molecules, or even identical.

Support for this speculation comes from the outcome of the cross-species experiments. Fish retinal axons respond to a repellent component on caudal membranes of the chick. PI-PLC treatment of the chick membranes abolishes the avoidance behavior that fish axons exhibit when exposed to alternating stripes of chick rostral and caudal membranes. Thus fish axons probably recognize the same component on chick membranes, as do chick axons. Moreover, fish axons also respond to the age-dependent decline of the repellent component in chick. Therefore it is not unlikely that the components on fish and chick membranes are structurally similar and so similar that cross-species recognition is allowed. This idea is substantiated by an earlier report of Godement and Bonhoeffer ('89), who showed that temporal axons from a mammal, the mouse embryo, accumulate on rostral membranes on a striped carpet of membranes from chick.

There are, however, some differences - as judged by the response of the fish axons-between fish and chick caudal membrane components that remain to be considered. In the chick, heat treatment of the caudal membranes inactivates the repellent influence, whereas the general growth permissivity of the membranes is preserved (Walter et al., ' $87 \mathrm{~b}$ ). The temperatures required for inactivation of the chick component are too high to use with fish membranes because they loose their growth permissivity (at $49^{\circ} \mathrm{C}$ ) before there is any evidence that the repellent component has been disrupted. This and further differences between fish and chick guiding components can be interpreted in two ways. They may indicate that the fish and chick component are different molecules after all. Additional observations, however, are consistent with the idea that the concentration of the component and the sensitivity of the axons to it are different in the fish and chick. The chick repellent components appear to have a stronger effect on fish axons than the fish component. This could be explained if the chick component is present in higher concentrations than the one in fish. In fact, the chick repellent component can induce growth cone collapse and retraction of the fish temporal axons, but fish caudal membranes do not elicit such dramatic reactions (Bastmeyer, Vielmetter, and Stuermer, unpublished observations). Moreover, fish axons appear to have a higher sensitivity to the repellent component than chick axons. Evidences for these points are that the fish temporal axons are to some extent able to cross caudal membrane stripes of fish but hardly ever those of the embryonic chick. Moreover, caudal fish membranes reduce the outgrowth of fish temporal axons by roughly $50 \%$ when 
compared to the outgrowth rate on rostral fish membranes. They do not reduce the outgrowth of fish nasal axons. Caudal membranes of the E9 chick, however, suppress the outgrowth of fish axons almost entirely and also reduce the outgrowth rate of fish nasal axons. Fish nasal axons normally grow randomly over the stripes with fish membranes (Vielmetter and Stuermer, '89). However, they segregate on rostral membranes, if exposed to rostral/ caudal striped carpets of chick membranes. This shows further that fish nasal axons possess a sensitivity to the deflecting component, but to a lesser degree than fish temporal axons. Although they accumulate on chick rostral membranes, the nasal axons are able to cross the chick caudal membranes to a certain extent and are able to, although in reduced number, extend on chick caudal membranes. Thus they behave like fish temporal axons on fish membranes. The response of fish nasal axons to the chick caudal membranes is abolished in the conditions mentioned under which chick caudal membranes have no or a weaker deflecting force on temporal axons (i.e., after PI-PLC treatment and on E16 chick membranes). This observation implies that fish nasal axons respond to the very same component as fish and chick temporal axons.

The finding that fish nasal axons respond to the chick repellent component was unexpected since chick nasal axons, at least in the choice assay, do not. When a segment extending from nasal to temporal extremes of the retina of chick is explanted onto the striped carpet, a boundary at the position of the optic fissure exists between repellent component-responding temporal and nonresponding nasal axons (Walter et al., '87a). The sensitivity of fish nasal axons to the chick component indicates that-at least in fish-a clear separation in sensitive temporal and nonsensitive nasal axons does not exist. Both only differ in the strength of their response or their sensitivity. This probably applies also to chick retinal axons. When a suspension of caudal membranes in a so-called collapse assay is given onto the growing axons, temporal growth cones collapse almost always (Cox et al., '90). Collapse of nasal growth cones is less frequent, however, is observed in $30 \%$ of all experiments (Müller et al., '90). Whether chick nasal axons would, in the choice assay, respond like fish axons upon exposure to an increased concentration of the repellent component over the level present normally is not known.

Mouse retinal axons have been shown also to recognize differences between rostral and caudal membranes derived from embryonic mouse superior colliculus (Godement and Bonhoeffer, '89), the homologous structure to the tectum opticum of nonmammalian vertebrates. Furthermore, mouse temporal axons respond to rostral/caudal membrane differences of chick tecta and accumulate on the rostral membranes. These findings, together with the results presented here, reinforce the suggestion that the positionspecific retinal and tectal cell components may be evolutionary conserved (Godement and Bonhoeffer, '89).

Direct evidence that the repellent component which deflects axons in vitro is a guiding component for retinal axons in vivo is still missing. However, the comparison of its spatial and temporal regulation in fish and chick revealed by the in vitro assays increase the likelihood that it does. First, in the fish and chick the guiding component is, as expected, associated with tectal cell surfaces, exhibits in both an uneven spatial distribution, which correlates with an uneven and matching distribution of sensitivities on the retinal axons, and is expressed on the membranes over time periods over which axons in vivo require guiding compo- nents in order to find their retinotopic target. The time periods over which the guiding component is made available during development is different in the chick and fish but correlates with the different modes of retinotectal development in these two species.

\section{ACKNOWLEDGMENTS}

We thank Dr. Friedrich Bonhoeffer for introducing us into the in vitro choice assay and for stimulating discussions. Dr. Nancy Hopkins corrected and gave helpful comments on the manuscript. We acknowledge most gratefully the excellent technical assistance of Marianne Wiechers.

\section{LITERATURE CITED}

Bonhoeffer, F., and A. Gierer (1984) How do retinal axons find their targets on the tectum?. TINS 7:378-381.

Brümmendorf, T., J.M. Wolff, R. Frank, and F.G. Rathjen (1989) Neural cell recognition molecule F11: Homology with fibronectin type III and immunoglobulin type $\mathrm{C}$ domains. Neuron 2:1351-1361.

Cox, E.C., B. Müller, and F. Bonhoeffer (1990) Axonal guidance in the chick visual system: Posterior tectal membranes induce collapse of growth cones from the temporal retina. Neuron 2:31-37.

Crossland, W.J., W.M. Cowan, and L.A. Rogers (1975) Studies on the development of the chick optic tectum. IV. An autoradiographic study of the development of retino-tectal connections. Brain Res. 91:1-23.

Easter, S.S.Jr. (1985) The continuous formation of the retinotectal map in goldfish, with special attention to the role of the axonal pathway. In G.M. Edelman, W.E. Gall and W.M. Cowan (eds): Molecular Bases of Neural Development. New York: The Neuroseiences Institute, pp. 429-452.

Easter, S.S., Jr., A.C. Rusoff, and P.E. Kish (1981) The growth and organization of the optic nerve and tract in juvenile and adult goldfish. J. Neurosci. 1:793-811.

Ferguson, M.A.J., and A.F. Williams (1988) Cell-surface anchoring of proteins via glycosyl-phosphatidylinositol structures. Annu. Rev. Biochem. 57:285-320.

Fraser, S.E. (1980) A differential adhesion approach to the patterning of nerve connections. Dev. Biol. 79:453-464.

Gaze, R.M. (1970) The Formation of Nerve Connections. London: Academic Press.

Gierer, A. (1987) Directional cues for growing axons forming the retinotectal projection. Development 101:479-489.

Godement, P., and F. Bonhoeffer (1989) Cross-species recognition of tectal cues by retinal fibers in vitro. Development 106:313-320.

Godement, P., J. Salaün, and M. Imbert (1984) Prenatal and postnatal development of retinogeniculate and retinocollicular projections in the mouse. J. Comp. Neurol. 230:552-575.

He, H.T., J. Barbet, J.C. Chaix, and C. Goridis (1986) Phosohatidylinositol is involved in the membrane attachment of NCAM-120, the smallest component of the neural cell adhesion molecule. EMBO J. 5:2489--2494.

Low, M.G. (1989) The glycosyl-phoshatidylinositol anchor of membrane proteins. Biochim. Biophys. Act. 988:427-454.

Low, M.G., and A.R. Saltiel (1988) Structural and functional roles of glycosyl-phosphatidylinositol in membranes. Science 239:268-275.

Müller, B., B. Stahl, and F. Bonhoeffer (1990) In vitro experiments on axonal guidance and growth cone collapse. J. Exp. Biol. 153:29-46.

Sperry, R.W. (1963) Chemoaffinity in the orderly growth of nerve fiber patterns and connections. Proc. Natl. Acad. Sci. USA 50:703-710.

Stuermer, C.A.O. (1989) Dynamics of axonal growth and the formation of orderly nerve connections in the fish retinotectal system. In H. Rahmann (ed): Progress in Zoology. Stuttgart: Gustav Fischer Verlag, pp. 103-116.

Vielmetter, J., and C.A.O. Stuermer (1989) Goldfish retinal axons respond to position-specific properties of tectal cell membranes in vitro. Neuron 2:1331-1339

Walter, J., S. Henke-Fahle, and F. Bonhoeffer (1987a) Avoidance of posterior tectal membranes by temporal retinal axons. Development 101:909-913.

Walter, J., B. Müller, and F. Bonhoeffer (1990) Axonal guidance by an avoidance mechanism. J. Physiol. (Paris) 84:106-110.

Walter, J., B. Kern-Veits, J. Huf, B. Stolze, and F. Bonhoeffer (1987b) Recognition of position-specific properties of tectal cell membranes by retinal axons in vitro. Development 101:685-696. 